\title{
Statistical Approach to Predict the Ischemic Heart Disease
}

\author{
Hanif A., ${ }^{1}$ Akhtar B., ${ }^{2}$ Butt A., ${ }^{3}$ Butt N.S., ${ }^{4}$ Khan B.Z., ${ }^{5}$ Sajid M.R. ${ }^{6}$ \\ Address for Correspondence: Asif Hanif: Biostatistician: ANNALS of King Edward Medical University (KEMU) and \\ Department of Orthopedic Surgery and Traumatology (DOST) Unit I Mayo Hospital Lahore Pakistan.
}

Objectives: The objectives of this study were to see the degree of dependency of Ischemic Heart Disease (I.H.D) on different risk factors and to develop a model to predict the probabilities of I.H.D in various situations.

Study Design: This was a retrospective study.

Setting: The data was taken from the Department of Cardiology Mayo Hospital Lahore.

Total Number of Patients: The record of 364 patients was taken who presented first time for coronary angiography at the Department of Cardiology Mayo Hospital Lahore.

Methods: Data was analyzed using SPSS 16. The age of patient's was presented in form of Mean \pm S.E. Binary Logistic Regression Model was used to estimate the probabilities of Ischemic Heart Disease (I.H.D). Odds Ratio was used to see the role of risk factors.

Results: Among $60.7 \%$ male and $39.3 \%$ female, the average age was $50.33 \pm 0.61$ years. In this study; Age, Gender, Body Mass Index, Smoking History, Diabetes Mellitus and Hypertension contributed to develop I.H.D.

Conclusion: Our study has shown that the risk of IHD increases with advancing age and low socioeconomic status significantly. The other factors like (smoking, Obesity, diabetes and hypertension) enhance the disease but are not significant.

Key Words: I.H.D, Logistic Regression, Odds Ratio, Risk Factors.

\section{Introduction}

Mortality figures due to cardiovascular disease have been increased from 14 to 16 million in all over the world during 1990 to $2000 .^{1,2}$ One of the fatal disease from group of cardiovascular disease is Ischemic Heart Disease (I.H.D). The prevalence of Ischemic Heart Disease (I.H.D) is 6.8\% in Pakistan and United States of America. ${ }^{3}$ The age-specific death rates for all cardiovascular diseases have declined in both developing and developed countries. But the rate for Ischemic Heart Disease (I.H.D) have augmented in some populations. ${ }^{4}$ The cause for this epidemiological change are many risk factors like; lack of proper exercises, imbalance diet, smoking, air pollution and perhaps fetal and childhood exposures that may multiply the risk of cardiovascular diseases in adulthood. ${ }^{5}$ Moreover the obesity and smoking are also cardiovascular risk factors with indisputable global boost up in recent decades. Smoking is currently extensive in most populations and in developing countries it has been causally associated with mortality for multiple cardiovascular diseases. ${ }^{6}$

Diabetes is another stronger predictor for I.H.D in women than in men. Dale AC et al 2007 published a study of 74914 patients in which 2100 presented with diabetes. Among people without diabetes men had twice (OR 2.20, CI 2.00-2.41) the rate of critical I.H.D compared with women. With the presence of diabetes, the gender gap was significantly reduced (OR 1.25, CI 0.9-1.72).

In addition we can prevent from the I.H.D if we explore and overcome on the factors which enhance the risk of
I.H.D. The present study was designed to identify the risk factors for I.H.D.

\section{Objectives}

The objectives of this study were to:

- See the degree of dependency of Ischemic Heart Disease (I.H.D) on different risk factors.

- Develop a model to predict the probabilities of Ischemic Heart Disease (I.H.D) in the presence of different risk factors.

\section{Material and Methods \\ Study Design: This was a retrospective study.}

Setting: The data was taken (retrieved) from the Department of Cardiology Mayo Hospital Lahore.

Total Number of Patients: The record of 364 patients was taken who presented first time for coronary angiography at the Department of Cardiology Mayo Hospital Lahore.

Methods: We took Ischemic Heart Disease (I.H.D) as a dependent variable with two Categories (No or Yes) along with a mixture of independent variables such as Age, Weight, Height, (weight and height were used to calculate Body Mass Index ), Gender, Socio Economic Status (S.E.S), Body Mass Index (B.M.I), Smoking History, Diabetes Mellitus (DM) and Hypertension (HT). 
The age of patient's was presented in form of mean \pm S.E. We also used Standard Deviation to see the variability of the age. Binary Logistic Regression Model was used to estimate the probability of Ischemic Heart Disease (I.H.D). Odds Ratio (O.R) was used to assess the extent of risks of independent variables on I.H.D. The formulae for Logistic Model is given as bellow:

$\mathrm{f}(\mathrm{z})=\mathrm{e}^{\mathrm{z}} /\left(1+\mathrm{e}^{\mathrm{z}}\right)$

Where $z=\beta_{0}+\beta_{1} X_{1}+\beta_{2} X_{2}+\beta_{3} X_{3}+\beta_{4} X_{4}+\ldots \ldots \ldots \ldots$ .. $\beta_{\mathrm{k}} \mathrm{X}_{\mathrm{k}}$

Also $\beta$ 's are coefficients and $\mathrm{k}$ denotes the number of independent variables. In logistic regression it is very important to note that $\mathrm{e}^{\mathrm{b}}=\mathrm{OR}$ which is same as $\mathrm{OR}=\mathrm{ad} / \mathrm{bc}$.

\section{Results}

Among $60.7 \%$ male and $39.3 \%$ female, the average age of patient's was $50.33 \pm 0.61$ years with $S . D=11.81$ years. According to the Omnibus test of model chi-square test = 41.974 with $p$-value $=0.000$, showing that the fitted logistic regression model is appropriate. (Table 1 ).

Table 1: Omnibus Tests of Model Coefficients.

\begin{tabular}{|l|c|c|c|}
\hline & Chi-Square & d.f & p-value \\
\hline Step & 41.974 & 7 & 0.000 \\
\hline Block & 41.974 & 7 & 0.000 \\
\hline Model & 41.974 & 7 & 0.000 \\
\hline
\end{tabular}

Logistic Model is appropriate and significant

Patient's age ( $\mathrm{p}$-value $=0.002$ ) and Poor Socio Economic Status ( $p$-value $=0.026$ ) played a significant role in the development of I.H.D. Most of the regression coefficients of independent variables were positive which indicates the positive relationship of risk factors with I.H.D. Gender OR shows that it plays protective role in the development of disease. Its negative value of regression coefficient shows that female have less chances to get this disease as compared to male. Age's OR (1.037), showing that there are 1.037 times more chances to have the I.H.D with one year increase in age. For our convenience we can say that there are 10.37 times more chances to have the I.H.D if we increase 10 years age. With the poor socio economic status there are 2.848 times more chances to have I.H.D. The Odds ratio of $\mathrm{BMI}=1.1$ tells that for obese people there are 1.1 times more chances to have I.H.D. Further more with the history of smoking there are 1.59 times more chances for I.H.D. In the presence of Diabetes Mellitus there is 1.06 times more chance to get the disease of I.H.D and there are 1.22 times more chances to have I.H.D in the presence of Hypertension. But C.I of Odds Ratio shows that Age, gender and Socioeconomic status are three significant factors in which age and Socioeconomic status playing role of risk factors but gender as protective factor for females.

\section{Model (Logistic Regression)}

According to (1.1), P (I.H.D) $=1 /\left(1+\mathrm{e}^{-\mathrm{z}}\right)$

Where: $Z=\beta 0+\beta_{1} X_{1}+\beta_{2} X_{2}+\beta_{3} X_{3}+\beta_{4} X_{4}+\beta_{5} X_{5}+\beta_{6} X_{6}+$ $\beta_{7} \mathrm{X}_{7}$

By putting the values of all $\beta$ 's and $X_{i}$ 's we get

$\mathrm{Z}=-.806+0.036$ (Age) -.964 (Gender) $+1.047(\mathrm{SES})+$ $0.083(\mathrm{BMI})+$ tension)

$$
0.466 \text { (Smoking) }+0.058((\mathrm{DM})+0.200 \text { (Hyper- }
$$

The probability of getting I.H.D for a male person having age 60 in the presence of all risk factors is given by P (I.H.D) $=0.923$ i.e. $92.3 \%$ chances for males to get I.H.D in the presence of listed risk factors. Similarly we can calculate the probability in certain situation by changing the values of different independent variables in the above given model.

\section{Discussion}

The average incidence of cardiac problem is $0.006 \%$ in men aged 30-69 and $0.002 \%$ in women. The incidence increases with age. ${ }^{8}$ Traditionally, CHD has been considered a disease of men. However, CHD is the leading cause of death in both men and women. ${ }^{9}$ In this study we also noted that the risk of I.H.D increases with the age and males are more likely to have the disease than female. During the last decades

Table 2: Variables in the Equation.

\begin{tabular}{|l|c|c|c|c|c|c|c|}
\hline & $\boldsymbol{\beta}$ & S.E. & Wald & $\boldsymbol{d} . \boldsymbol{f}$ & $\boldsymbol{P}$-value & $\boldsymbol{E x p}(\boldsymbol{B})=\boldsymbol{O R}$ & 95.0\% C.I. for EXP(B) \\
\hline Age $\left(\mathrm{X}_{1}\right)$ & .036 & .011 & 10.051 & 1 & .002 & 1.037 & $1.014-1.062$ \\
\hline Gender $\left(\mathrm{X}_{2}\right)$ & -.964 & .298 & 10.459 & 1 & .001 & .381 & $.213-.684$ \\
\hline S.E.S $\left(\mathrm{X}_{3}\right)$ & 1.047 & .471 & 4.931 & 1 & .026 & 2.848 & $1.131-7.175$ \\
\hline B.M.I $\left(\mathrm{X}_{4}\right)$ & .083 & .152 & .298 & 1 & .585 & 1.1 & $.806-1.464$ \\
\hline Smoking $\left(\mathrm{X}_{5}\right)$ & .466 & .367 & 1.615 & 1 & .204 & 1.594 & $.777-3.272$ \\
\hline Diabetes Mellitus $\left(\mathrm{X}_{6}\right)$ & .058 & .287 & .041 & 1 & .839 & 1.060 & $.604-1.858$ \\
\hline Hypertension $\left(\mathrm{X}_{7}\right)$ & .200 & .293 & .468 & 1 & .494 & 1.222 & $.688-2.170$ \\
\hline Constant & -.806 & .927 & .756 & 1 & .385 & .447 & \\
\hline
\end{tabular}


socioeconomic status (SES) has played a very significant role in the development of cardiovascular diseases in most industrialized Western countries, where disadvantaged groups practiced a higher risk for cardiovascular diseases. ${ }^{10}$ However, this contrary association is not consistently observed in developing or intermediary countries. Quite opposite, positive relations higher risk for cardiovascular diseases among advantaged groups have been identified for coronary heart disease in Hong Kong, Puerto Rico, and Pakistan, and some sub-Saharan African countries. ${ }^{11,12}$ According to our analysis poor socioeconomic status is a risk factor for getting Ischemic Heart Disease (I.H.D).

Yusuf S et al in 2004 published that obesity is an independent risk factor for CHD. Abdominal obesity is most significant. Those with central obesity have over twice the risk of heart attack. ${ }^{13}$ The analysis of this study also predicts that, the chance of I.H.D increase in obese patients. According to WHO that over $20 \%$ of CVD is due to smoking ${ }^{14}$ which is a threatening statistics for smokers. According to this there are 1.6 times more chances of I.H.D for smokers.

\section{Conclusion}

Our study has shown that the risk of IHD increases with increasing age and low S.E.S significantly. Females have less chance to get this disease as compared males. The other factors like (Smoking, Obesity, Diabetes and Hypertension) enhance the disease but are not significant.

\section{References}

1. Murray CJL, Lopez AD, eds. The Global Burden of Disease. Cambridge, Mass: Harvard School of Public Health, on behalf of the World Health Organization and the World Bank; 1996.

2. World Health Organization. World Health Report 2002: Reducing Risks, Promoting Healthy Life. Geneva, Switzerland: World Health Organization; 2002.

3. Bhatti IP, Lohano HD, Pirzado ZA, et al. A logistic regression analysis of the Ischemic Heart Disease Risk. Journal of Applied Sciences 2006; 6 (4): 785-88.

4. Yusuf S, Reddy S, Ounpuu S, Anand S. Global burden of cardiovascular diseases, part I: general considera- tions, the epidemiologic transition, risk factors, and impact of urbanization. Circulation. 2001; 104: 27462753.

5. Singhal A, Lucas A. Early origins of cardiovascular disease: is there a unifying hypothesis? Lancet. 2004; 363: 1642-1645.

6. Thun MJ, Apicella LF, Henley SJ. Smoking vs other risk factors as the cause of smoking-attributable mortality: confounding in the courtroom. JAMA. 2000; 284: 706-712.

7. Dale AC, Nilsen TI, Vatten L, et al. Diabetes mellitus and risk of fatal ischemic heart disease by gender: 18 years follow- up of 74914 individuals in the HUNT 1 Study. European Heart Journal 2007; 28 (23): 2924-29.

8. British Heart Foundation Statistics Database; Coronary heart disease statistics. 2007 edition.

9. Mikhail GW; Coronary heart disease in women. BMJ. 2005 Sep 3;331 (7515): 467-8.

10. Strand BH, Tverdal A. Can cardiovascular risk factors and lifestyle explain the educational inequalities in mortality from ischemic heart disease and from other heart diseases? 26-year follow-up of 50000 Norwegian men and women. J Epidemiol Community Health. 2004; 58: 705-709.

11. Chang CL, Marmot MG, Farley TMM, Poulter NR. The influence of economic development on the association between education and the risk of acute myocardial infarction and stroke. J Clinical Epidemiol. 2002; 55: 741-747.

12. Hameed K, Kadir M, Gibson T, Sultana S, Fatima Z, Syed A. The frequency of known diabetes, hypertension and ischemic heart disease in affluent and poor urban populations of Karachi, Pakistan. Diabetes Med. 1995; 12: 500-503.

13. Yusuf S, Hawken S, Ounpuu S, et al; Effect of potentially modifiable risk factors associated with myocardial infarction in 52 countries (the INTERHEART study): case-control study. Lancet. 2004; 364 (9438): 937-52.

14. Guilbert JJ; The world health report 2002 - reducing risks, promoting healthy life. Educ Health (Abingdon). 2003; 16 (2): 230. 